\title{
Research on the Problems and Countermeasures of China's Sporting Goods Manufacturing Industry in Olympic Marketing
}

\author{
Zhen Bai ${ }^{1}$, Han Yang ${ }^{2 *}$ \\ ${ }^{1}$ Institute of physical education and health, research center for physical education reform and \\ development, College of physical education, Henan University, Kaifeng 475001, Henan, China \\ ${ }^{2}$ Henan University, school of pharmacy, KaiFeng, 475000, Henan, China \\ *Corresponding Author.
}

\begin{abstract}
"Sports marketing" is a very popular marketing method today. With the upcoming 2022 Beijing Winter Olympics, "Olympic marketing" has become a new way for sporting goods manufacturing industry to enhance brand value and realize brand leap. Using the method of literature review, this paper summarizes the existing problems of domestic sporting goods manufacturing industry in the process of Olympic marketing, and puts forward the corresponding marketing strategies for everyone to discuss.
\end{abstract}

Keywords: Marketing of sporting goods manufacturing industry; Olympic marketing; Brand;

\section{Introduction}

The quadrennial Olympic Games are the world's top sports event. Its powerful appeal and attraction ability are self-evident. It is a manifesto for human beings to challenge their own limits. The number of participating countries, the number of people and the length of the schedule are beyond the reach of any other sport events. Therefore, Olympic marketing has been accepted by more and more companies and has become an effective way of product market and brand building.

Olympic marketing is to use various Olympic-related content (products, characters, events, services) as the carrier, so that enterprises and consumers establish a brand culture system with Olympic culture as the core, so as to combine the products (services) of enterprises with the connotation of the Olympic spirit. The Olympic sports spirit of "faster, higher and stronger" symbolizes the spirit of human beings to challenge themselves. This is the value of sports and is valued by entrepreneurs, hoping to transform it into the value of corporate spirit through Olympic marketing. The humanistic spirit conveyed by the Olympics will bring added value to the corporate brand, creating a positive connection between the brand and the Olympics, and virtually enhancing and extending the value of the brand. With the approaching of the Beijing Olympics, it has attracted more and more attention from the public and many companies. At the same time, Olympic marketing has also been accepted by more and more Chinese companies and has become an effective means of product marketing and brand building.

\section{The Charm of Olympic Sports Marketing}

\subsection{Olympic Marketing Being Charitable and Acceptable}

The biggest feature of Olympic marketing is with public welfare, so it is easy to be accepted. Its function is beyond the reach of ordinary advertising, and its effect is even more difficult to achieve in enterprise publicity.

\subsection{Olympic Marketing Having Great Appeal}

Olympic marketing is essentially a kind of soft advertising. But because its advertising does not appear alone, commerciality and utilitarianism are not as obvious as hard advertising. It can often make use of sports events to

ISSN: 0010-8189

(C) CONVERTER 2021 
create news, producing a lasting and moving sensation, and having a subtle and positive impact on product sales [1].

\subsection{Olympic Marketing’s Communication Object with Wide Range, Large Quantity, and Being Targeted}

At the scene of major competitions, there are tens of thousands of audiences, and the media audiences are countless. Even for some local events, as long as they are well organized, the audience will be very enthusiastic, which is very conducive to effective communication between the enterprise and the target object, and achieve a multiplier effect with half the effort.

\subsection{Olympic Marketing Being Low-Cost}

Low-cost sports marketing can reduce corporate marketing expenses. Among all the sports marketing methods, sports sponsorship is the most attractive and most popular with manufacturers because it is the most concentrated, comprehensive and strongest embodiment of all the advantages of sponsorship.

The benefits of using Olympic marketing are obvious. Many well-known companies in the world established their global brand images in the process of sponsoring the Olympics. For a company to increase its brand awareness worldwide, every $1 \%$ increase requires USD20 million in advertising expenses, but with the help of large-scale sports competitions, it can increase by $10 \%$ with the same amount of expenses. Many popular international brands, such as Adidas, Nike, Coca-Cola, Pepsi, etc., have a deep connection with the Olympic Games. A large number of cases show that the significance of the Olympics for corporate marketing lies in: first of all, the Olympics has set off a climax of attention. Secondly, it can surpass competitors in competition. More importantly, sports can enhance brand equity including awareness, enhance brand taste and positioning, and make consumers believe in the corporate brand. Therefore, companies can take advantage of the good opportunity of the Olympic Games to achieve marketing goals.

\section{Existing Problems of Chinese Enterprises in Olympic Marketing}

3.1 Monotonous Corporate Olympic Marketing Strategy without Creativity or Concept of Integrated Marketing Communication

The most commonly used marketing strategies for Chinese companies are: advertising bombing and huge-amount lottery draws. There is no changes of tricks or new ideas. For example, as soon as we turn on the TV, we will see the advertisement of "melatonin "... As time passes, everyone is like avoiding the plague, and they change channels as soon as they watch this advertisement. This monotonous marketing strategy is much worse than an integrated marketing strategy, which means all-round marketing that various marketing methods are integrated and used.

\subsection{Financial Pressure Preventing Enterprises from Olympic Marketing}

Enterprises sponsor the Olympic Games and invite Olympic champions to be spokespersons for nothing more than to expand the awareness and reputation of the corporate brand. However, after throwing out a huge amount of sponsorship costs, it is not known whether the later promotional expenses can be sufficient. That is to say, the enterprise lacks sufficient verification funds and is under pressure from the scale of funds. It is known that the threshold for the sixth round of global sponsors has increased from the original USD4 million to about USD80 million. The marketing costs of Coca-Cola's specific investment are 3 to 5 times the sponsorship fee, and it is predicted that its later promotion fee is about 10 times the sponsorship fee. Such an astonishing number can only be "consumed" by large brand companies, while for small companies, it can only be prohibitive.

\subsection{Short-Sighted Company Lacking Long-Term Strategic Planning and Pursueing Pure Event Marketing}

ISSN: 0010-8189

(C) CONVERTER 2021 
Olympic marketing is by no means through once or twice creative hype to have an impact on sales. Instead, enterprises should make full use of the Olympic brand resources and organically combine the Olympic brand with corporate characteristics through a series of marketing strategies to promote brand awareness and image, and convey the core connotation or core cultural proposition of the brand to the target consumers, the core of which is to integrate the Olympic culture into the enterprise itself. For example, Coca-Cola Company in the United States has been carrying out Olympic marketing since the 9th Amsterdam Summer Olympic Games in 1928. It has become the longest-term partner of the Olympic Games, and its brand image is deeply rooted in the hearts of the people. On the contrary, most domestic companies only care about short-term popularity and sales targets, and they often rush to launch and make a desperate move.

\subsection{The Week Exploitation on Olympic Champions' Commercial Value}

At present, the exploitation of the commercial value of the Olympic champions is very weak. Basically, they are only image spokespersons and participating in some activities. Their commercial value cannot be fully developed. The reason is the "national sports" system. Once you become an athlete trained by the country, it also means you will lose some or all of your "dominance". Instead, the country has "complete control" over athletes, and the General Administration of Sports will take over the management responsibilities. For example, the sports authority strictly demanded all Olympic champions not to accept business plans outside without authorization within one and a half months after returning from Athens. Another example is that Chinese Athletic Association clearly stated that Liu Xiang can only serve as the image spokesperson for up to four brands. The commercial value of champions is difficult to achieve a premium, and companies have also lost some opportunities for product promotion [2].

\subsection{Lacking Creative Spirit and Being Hard to Catch the Entry Point}

When it comes to innovation, it's a cliche. All companies are talking about how they pay attention to innovation, but what they show is completely different. There are few innovative bright spots in the sports marketing of the whole home appliance industry. They are all cookie-cutter advertisements, buying gifts, lowering price, etc. For Olympic marketing, companies lack the entry point, and marketing cannot take root and become a castle in the sky. Through some boring advertising bombardment, consumers can only be given aesthetic fatigue, and they can't play a substantive role in promoting. In fact, big events like the Olympic Games are an excellent opportunity for companies to fully communicate with customers. When conducting Olympic marketing, enterprises should analyze and understand consumers' inner needs, and adopt strategies to attract them. For consumers who are becoming smarter and smarter, it is difficult to use some low-level promotional methods that "wool out of the sheep" to bamboozle consumers through straightforward price wars. In fact, consumers are emotional, but sometimes they will show a rational side, but there are almost no real rational consumers. Therefore, in China, where emotion is especially emphasized, the use of emotional marketing becomes more important and effective. Certainly, this does not mean to be sensational. Successful marketing and valuable marketing are always based on respect and creation of customer value.

\section{Countermeasures for Chinese Enterprises to Implement Olympic Marketing}

\subsection{Formulating an Integrated Marketing Communication Plan to Closely Integrate Brand Strategy with Olympic Marketing}

As a major international sports event, Olympic Games's economic benefits and role of promoting the spread of brand value are unquestionable. However, we must realize that sports marketing is a complicated system implementation process. It requires enterprises to re-integrate resources under the guidance of sports marketing, and realize the integration of sports culture, brand culture and corporate culture, so as to arouse resonance between consumers and enterprises, and promote the growth of corporate brand value and sales. Therefore, we cannot treat

ISSN: 0010-8189

(C) CONVERTER 2021 
the Olympic Games as an isolated "marketing event", but should regard it as an important link in the company's long-term communication strategy that warm up before the event, intensively spread during the event, and consolidate it afterwards. In other words, the Olympic Games itself will pass quickly, but companies must be good at grasping the extended activities, lengthen and enlarge them as much as possible in time and space. Through the imported communication of the early stage, the strengthening of the communication during the competition, and the consolidation communication after the competition, the company's brand and sports activities are closely integrated, so that the company can achieve a good communication effect in a relatively long period of time with less investment.

\subsection{Rooting the Marketing Strategy in the Olympic Spirit and Chinese Culture}

Olympic marketing should explore the cultural connotation of the Olympics. The significance of the Olympics is not only the competitive nature of the games, but also the spirit and culture. "One World, One Dream", "Green Olympics, Humanistic Olympics, High-tech Olympics" etc. reflects the cultural connotation of the 2008 Beijing Olympics. For enterprises, Olympic marketing does not simply add the Olympic "stigma" to the marketing of products and brands to represent the use of Olympic marketing. In fact, high-level Olympic marketing cannot be just for the pursuit of fashion and deliberately integrate the Olympics in the promotion activities. It is necessary to be able to organically integrate the Olympic spirit with the corporate brand culture, and realize the docking of corporate brand elements and Olympic cultural connotations.

\subsection{Insisting on the Combination of Creativity and Ingenuity in Sports Marketing}

Many companies have fallen into the same situation in their marketing methods. For example, no matter what product, they advertise by using slogans "wear XX to watch the Olympics", "drink XX to watch the Olympics", etc. It is difficult to impress consumers with such results. Therefore, the most important thing for Olympic marketing is to have good ideas. For example, Coca-Cola's sports marketing activities during the Olympic Games, apart from the constantly appearing Coca-Cola logo, there was no confession or boast about itself. However, through those meaningful plots and activities, the audience unknowingly and convincingly understood Coca-Cola's good intentions, making its image and intentions seamlessly penetrate into people's daily lives. This intuitive, with non-commercial atmosphere, compulsory, interesting and natural, mixed communication effect is very natural and implicit, hidden and organic, and it is amazing.

\subsection{Choosing Suitable Strategic Partner}

Among all the communication platforms for major sports events such as the Olympics, TV stations are the most traditional promotion center, and they are also media with the fastest communication speed and the most obvious effect. Therefore, cooperation with TV stations that conduct live events is the first consideration for many companies. However, the TV broadcast fee of the Olympic Games is an astronomical figure. The choice of enterprises to cooperate with mainstream media such as CCTV means that they have to invest huge amount of money Naturally, this is not something that every company can do, nor is it something that companies need to invest as long as they have money. It depends mainly on what stage of development the company is in, and whether it is worth the cost. If it is a company with business all over the country, having gone through the start-up stage and entering the period of brand creation, it is good to choose to cooperate with mainstream media such as CCTV. If the company itself is small in scale, and it is only a regional brand, there is no need to invest without cost. It is best to wisely choose to cooperate with local mainstream newspapers and the Internet to maximize the benefits of communication. In fact, even if it is a national company, don't just stare at the TV station, because now the Internet, mobile phones, wireless communications, blogs and other new carriers are taking shape and are showing an ascendant momentum. Therefore, enterprises should choose the most suitable strategic partner among them according to their actual conditions.

ISSN: 0010-8189

(C) CONVERTER 2021 
4.5 Setting a Standard Evaluation System to Make a Qualitative and Quantitative Real-Time Evaluation and Analysis of Olympic Marketing

The marketing activities of enterprises need to invest a lot of capital, manpower and various resources. The final "return on investment" needs to be evaluated and summarized qualitatively and regularly at the same time as the implementation of marketing activities. The evaluation includes three levels: (1) Brand exposure rate. That is to evaluate the scale and reach rate of media attention (including audience rating, listening rating, browsing rating, etc.), by which the size of the population affected by Olympic marketing and the equivalent value of media advertising can be calculated. (2) Qualitatively study the changes in the audience's impressions and feelings of your brand or products that are affected by sports activities. (3) The terminal reflection of sports marketing in the early, mid and late stages. In addition, sports competitions are very contingent, and the results of the competitions are often unexpected. Therefore, when a company decides to sponsor a team and invite a player to be a brand spokesperson, it must fully consider the possible consequences and formulate corresponding countermeasures in advance. It is necessary to correctly evaluate the coefficient of the company's investment and the possible benefits, and try the best to control it within the company's acceptable range.

In short, Olympic marketing provides enterprises with a broad development platform. Enterprises should make full use of the Olympic marketing platform to create a more brilliant market effect, and pay attention to improving product quality and service, so as to achieve brand leap and enhance international competitiveness.

\section{References}

[1] F. Chen, "Strategic Choice of Enterprise's Olympic Marketing under Integrated Marketing Communication,” Marketing. April, pp. 81-82, 2007.

[2] Z.C. Wen, “A Preliminary Study of Enterprise's Olympic Marketing,” Market Weekly, pp. 45-47, June, 2006. 